\title{
Introduction to Data Collection
}

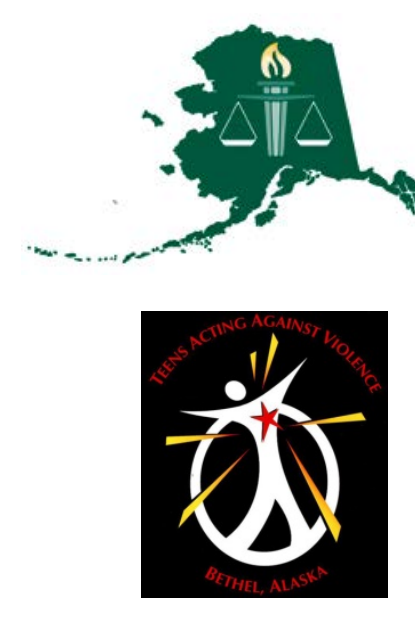

Andre B. Rosay

Justice Center, University of Alaska Anchorage

Michelle DeWitt

Bethel Community Services Foundation

December 5, 2013 


\section{Presentation Overview}

- Teens Acting Against Violence (TAAV) Program

- Data Collection Framework

- Doing Data Collection:

- Why?

- What?

- When?

- Who?

- How?

- Key Findings from TAAV Evaluation 


\section{Teens Acting Against Violence}

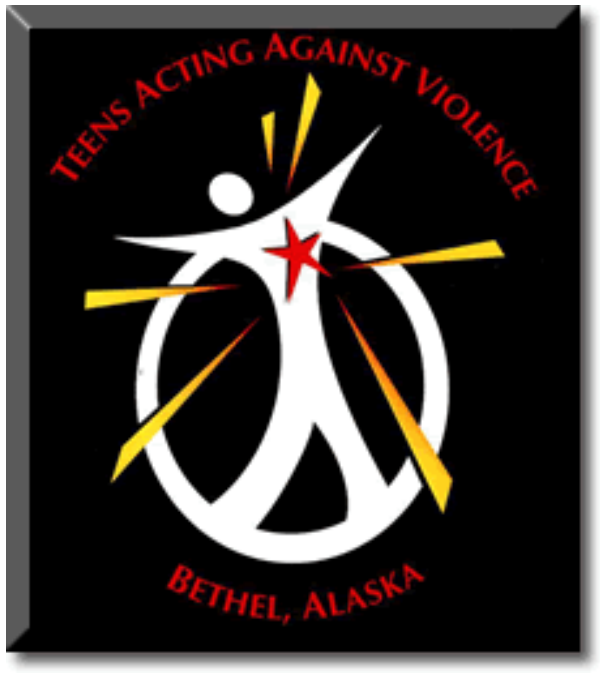

Teens Acting Against Violence (TAAV) is a violence prevention and youth empowerment program at the Tundra Women's Coalition for teenagers living in Bethel.

Focused on peer education and outreach, TAAV members speak out to engage peers about issues such as violence, abuse, and suicide through discussions, activities and the experiences and wisdom of other members.

http://tundrapeace.org/programs/taav/ 


\section{TAAV Prevention Philosophy}

Services to Teens is a Critical Piece of TWC and What We Do Every Day...

Leadership Development Cultural Relevance

Work Experience

Skill Building

Healthy Activities

Teen Empowerment
Outdoor Recreation
Peer Education

Crisis \& Family Work 


\section{Philosophy: \\ Peer Education}

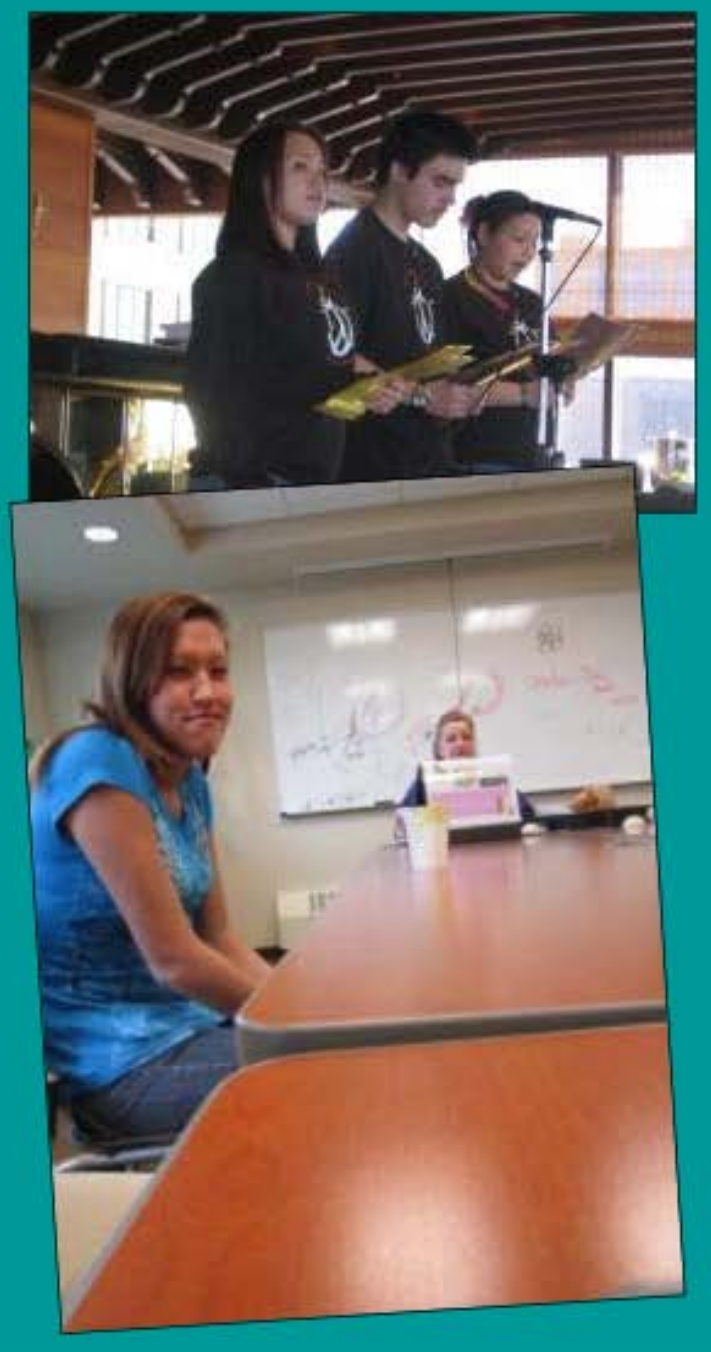

\section{Healthy Relationships}

\section{Expect Respect}

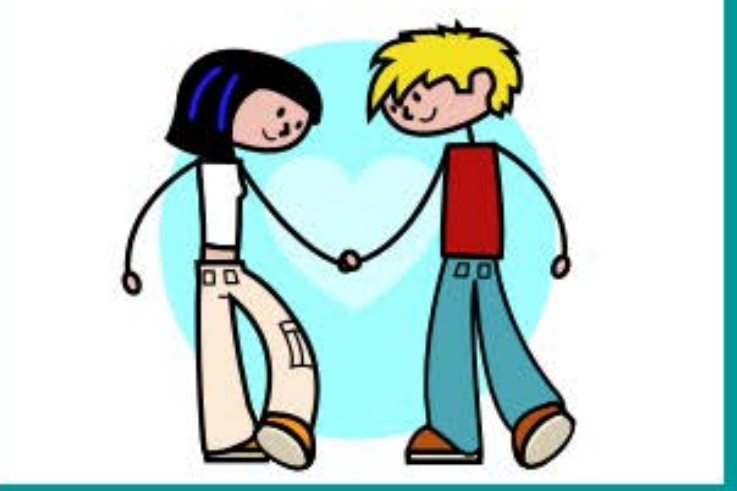

Talk the talk \& walk the walk! 


\section{Work Experience}

\section{Philosophy:}
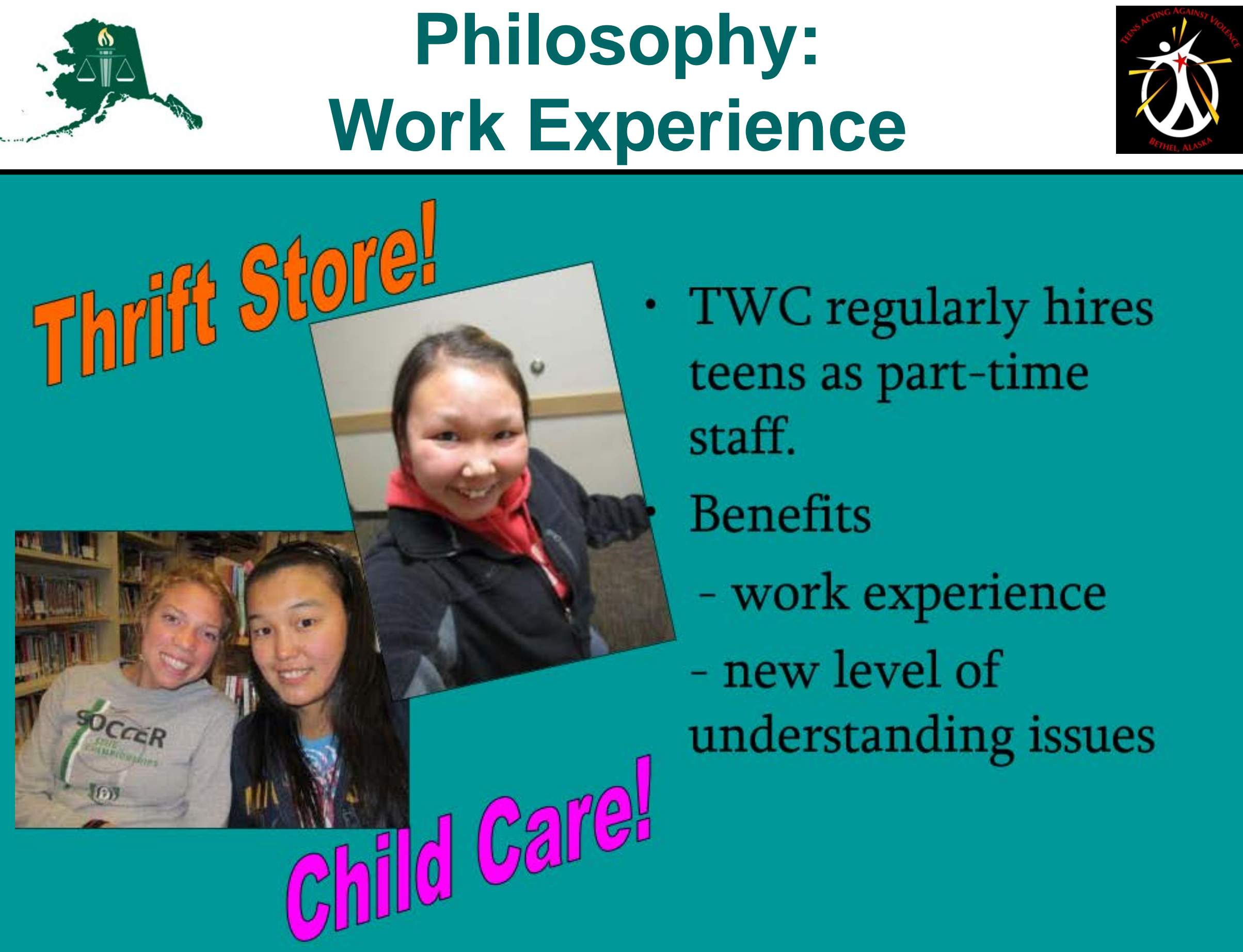

TWC regularly hires teens as part-time staff.

Benefits

- work experience

- new level of

understanding issues 


\section{Healthy Activities}

Philosophy:

son

\section{Alternatives to At-Risk Behaviors}

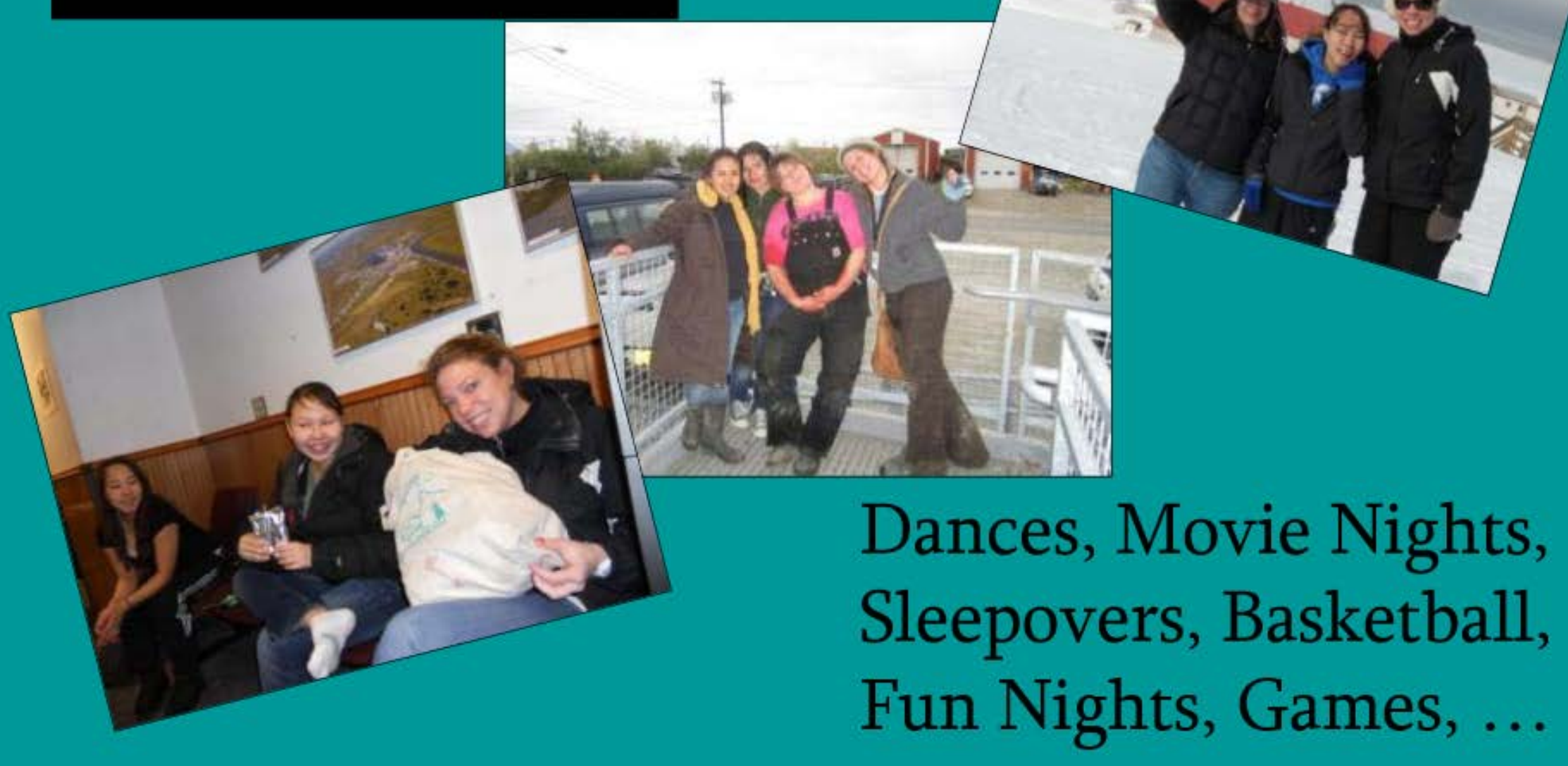




\section{Outdoor Education}

\section{Philosophy:}

- Our group needs opportunities to succeed at challenges!!

- Self-esteem building, skill-building and motivating trips
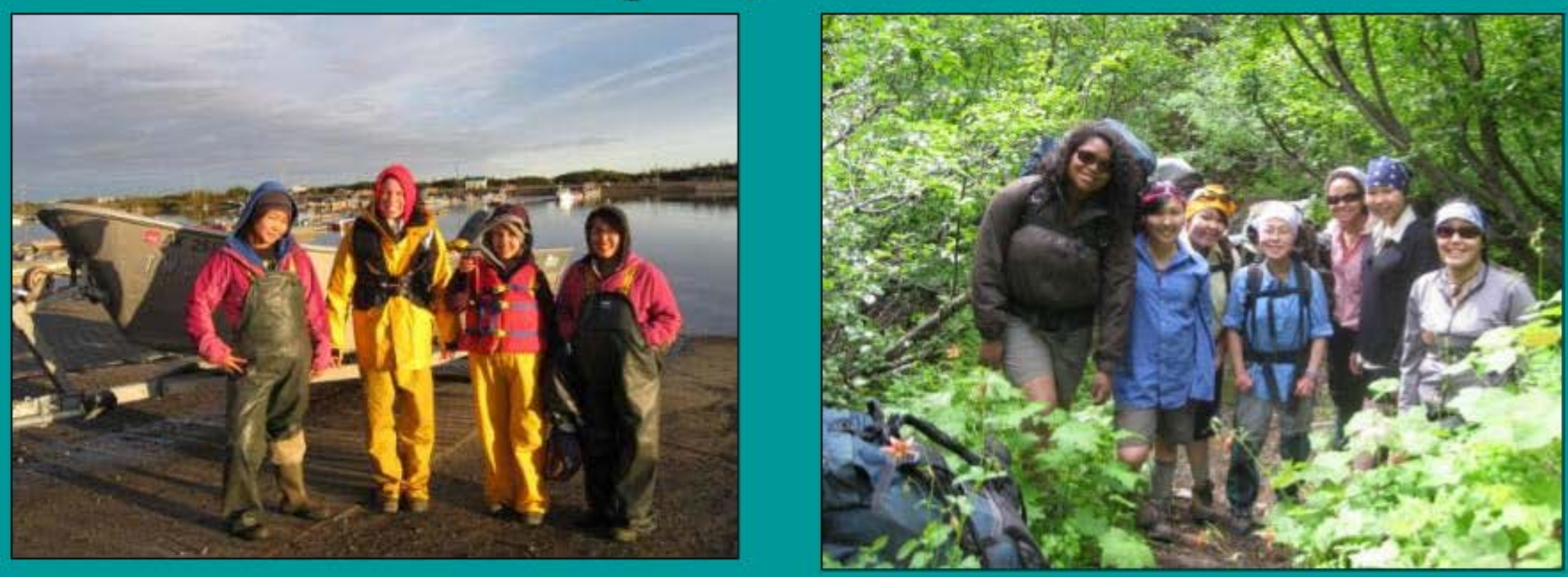

Annual Outward Bound trip! 


\section{Cultural Relevance}

\section{Philosophy:}

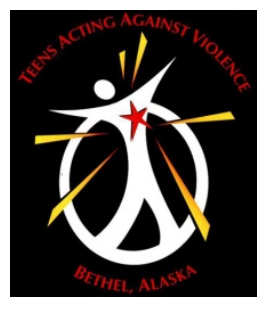

Our program must relate to rural, Alaska Native teens
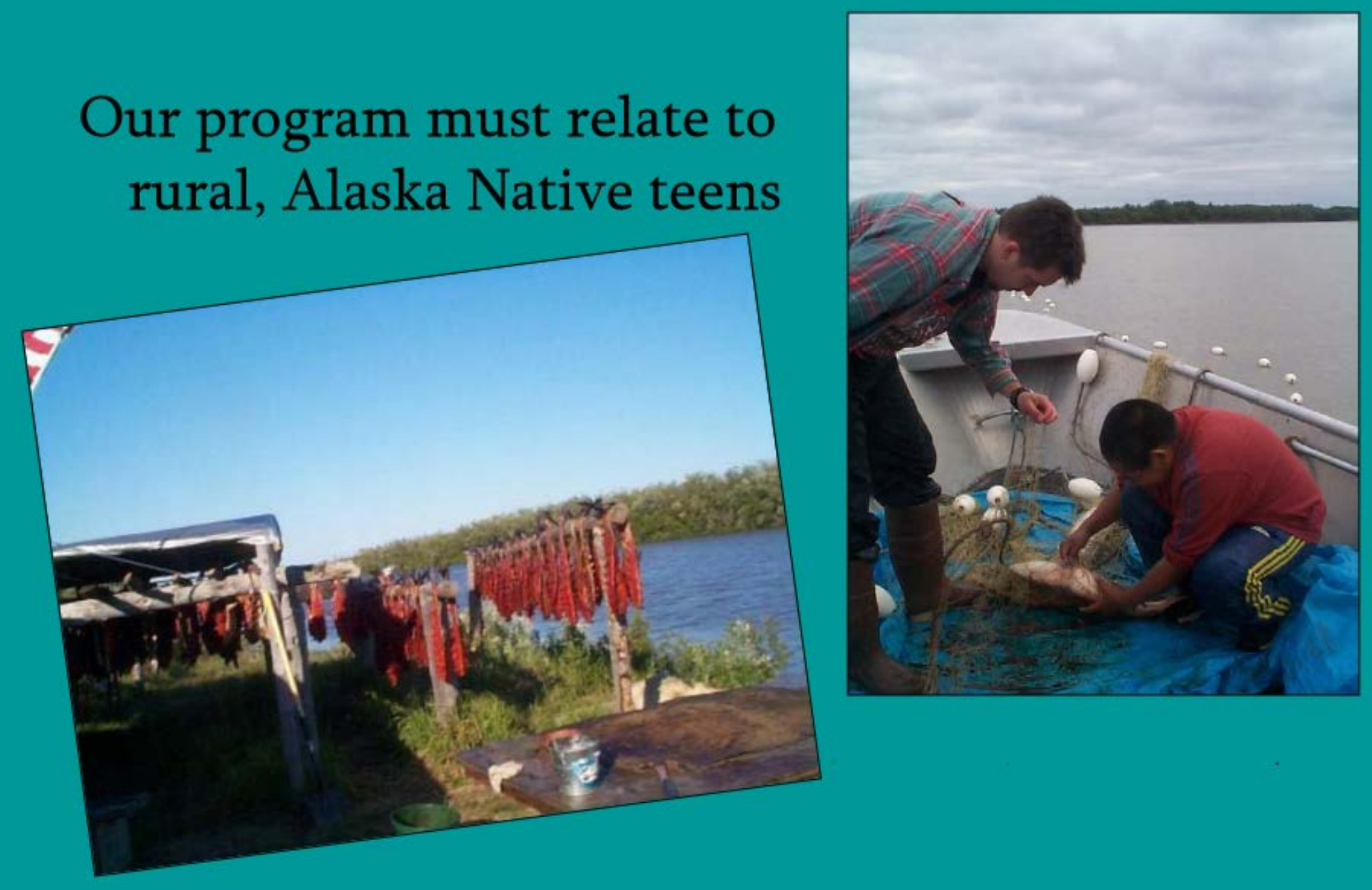


\section{Teen Empowerment}

\section{Philosophy:}

\section{Speaking Up \& Speaking Out!}

-Public Service Announcements
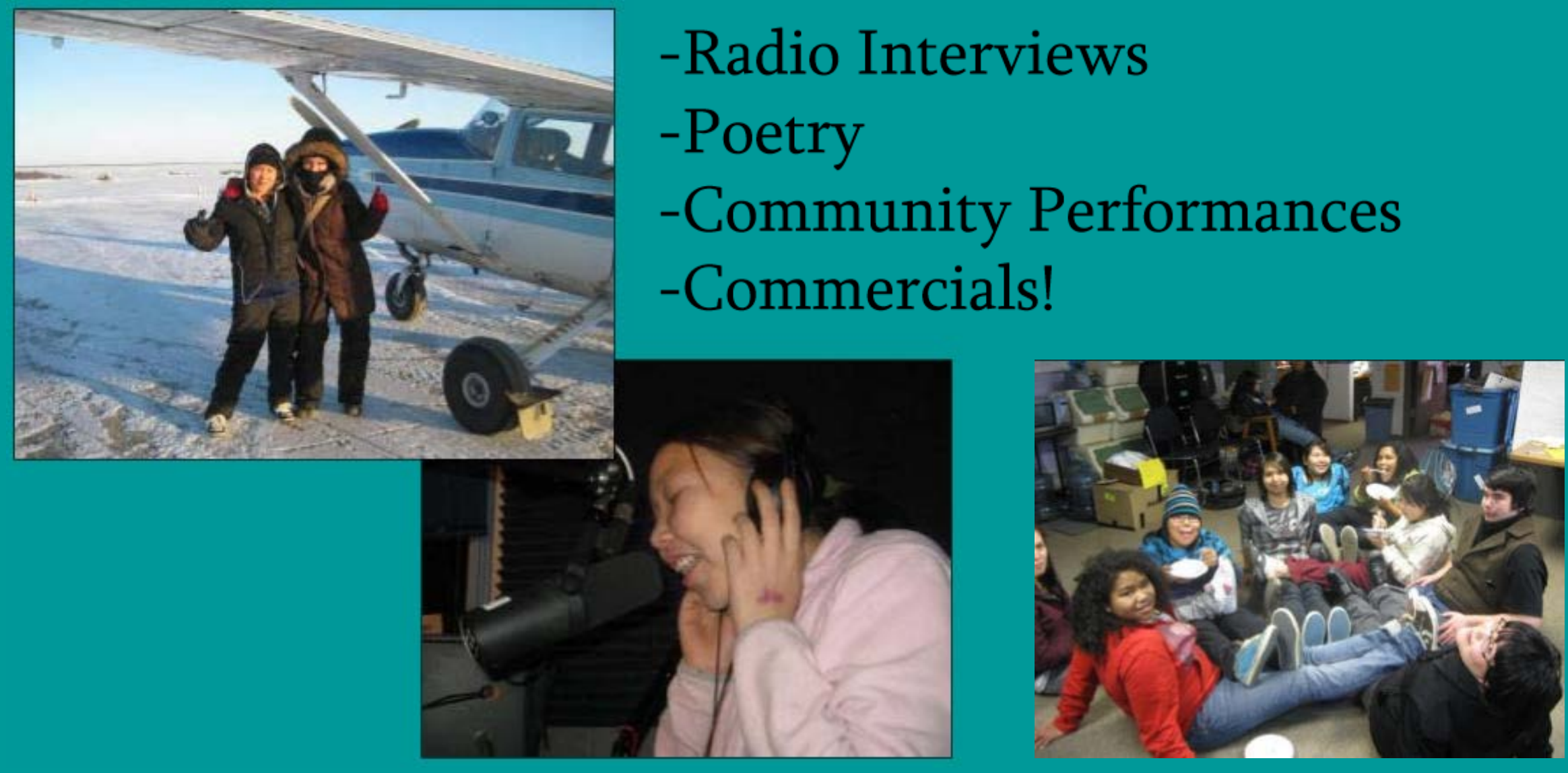


\section{Teens Lead Ahead}
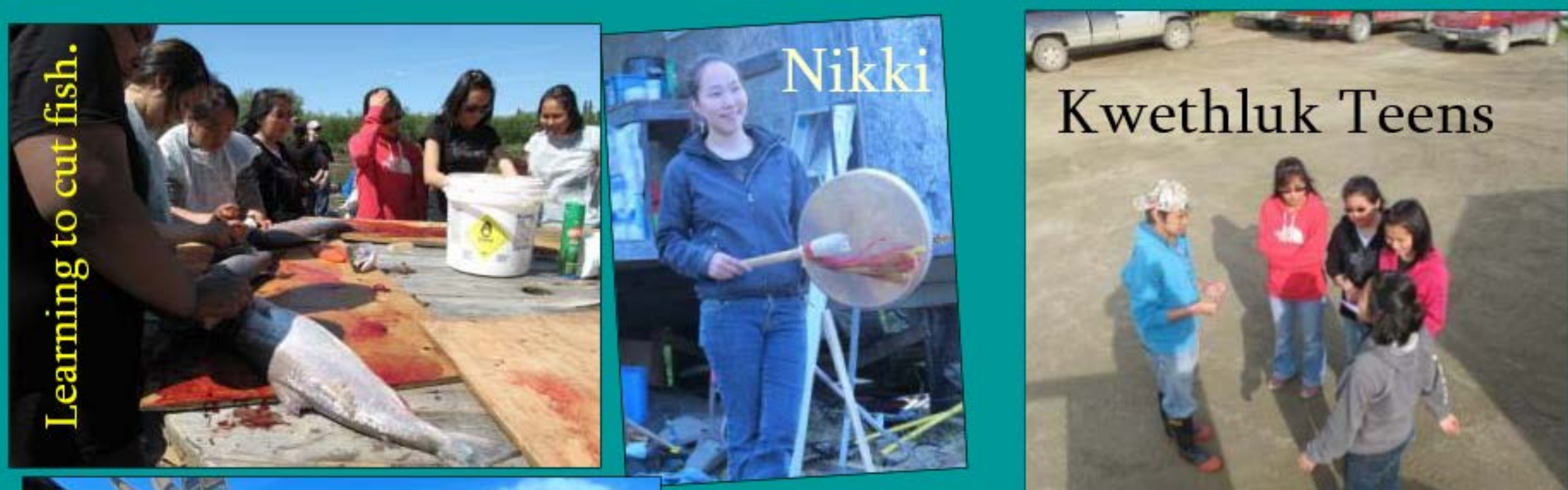

Kwethluk Teens

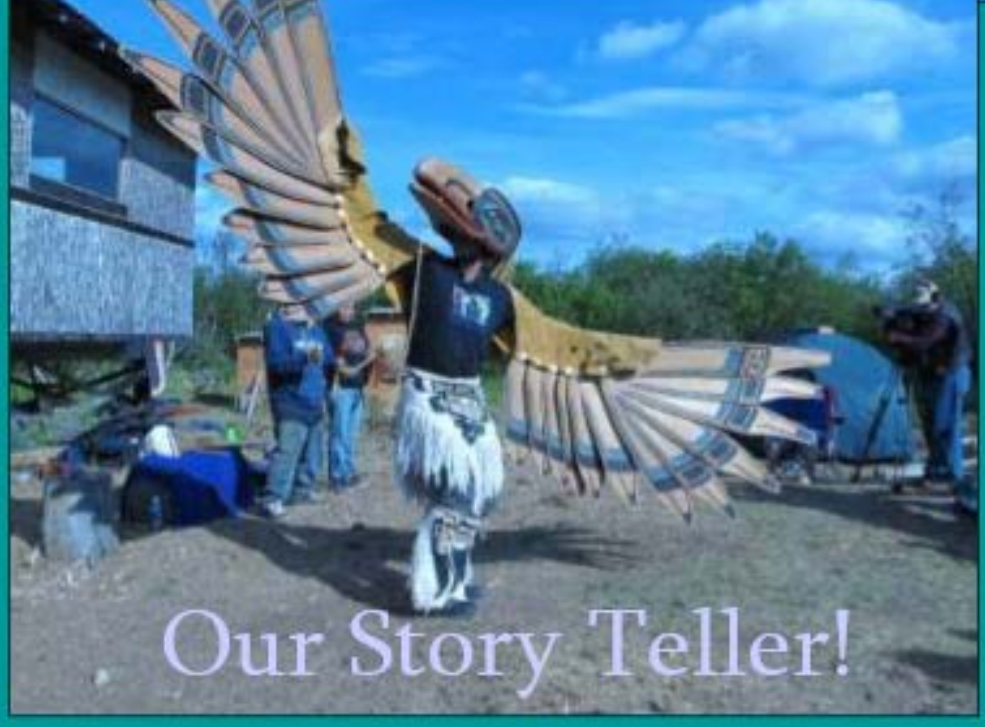

\section{Walking Along the River ..}

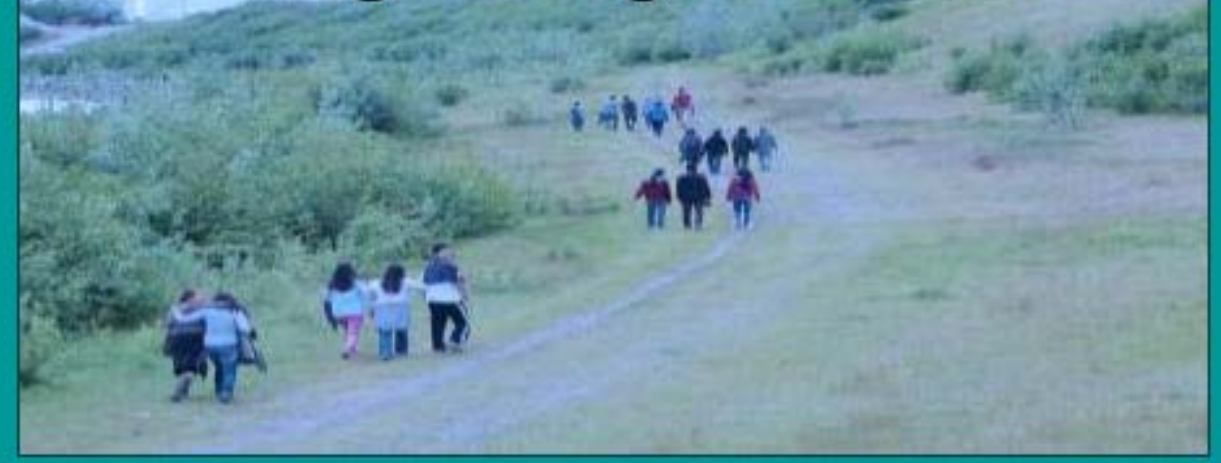




\section{Outward Bound}

Annual Outward Bound trips build skills

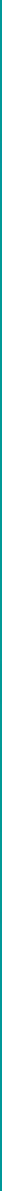




\section{Local Outdoor Activities}

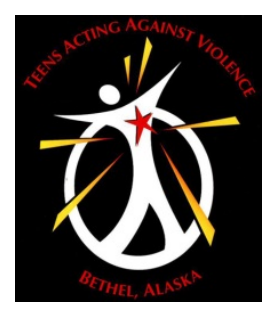

Moose Hunting
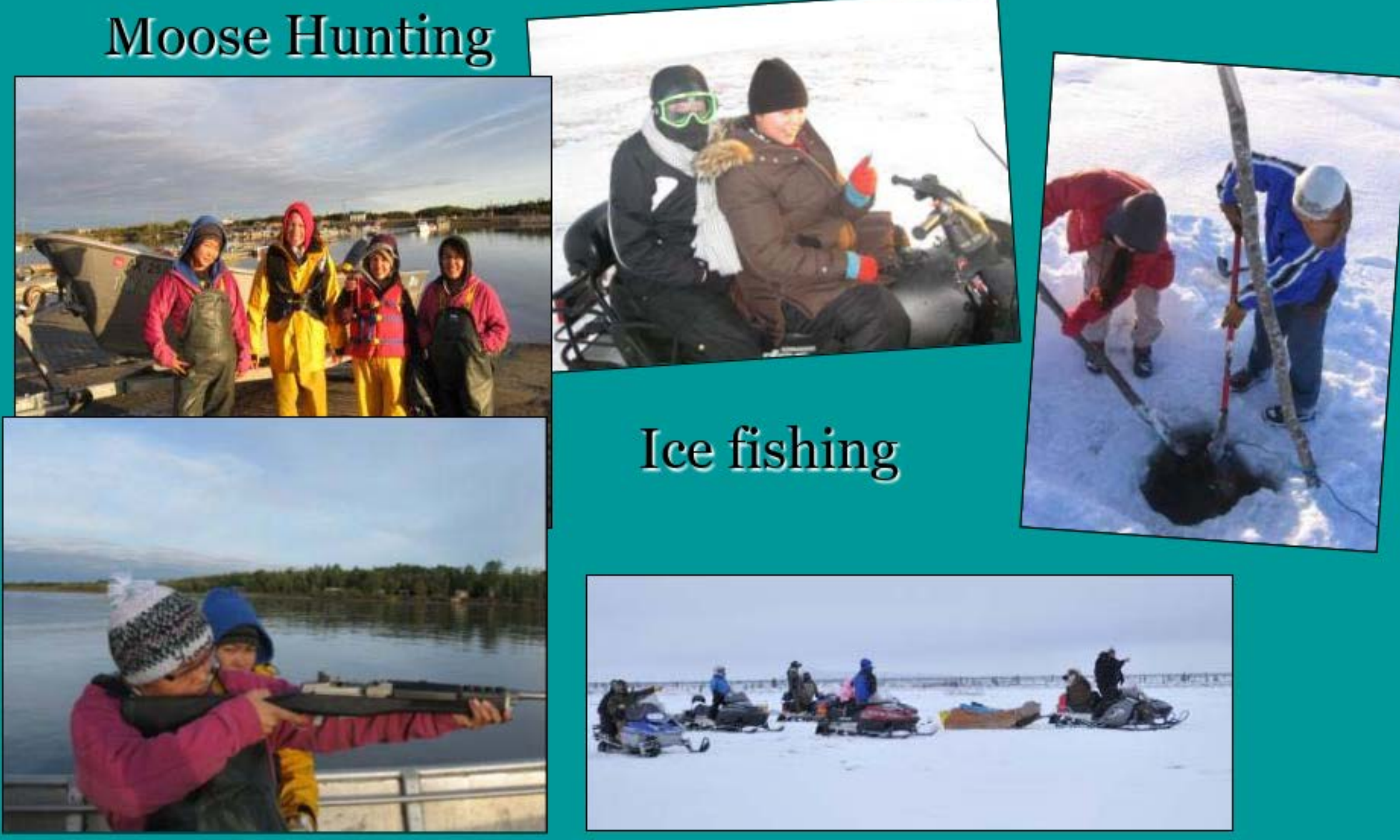


\section{Steps in \\ Data Collection}

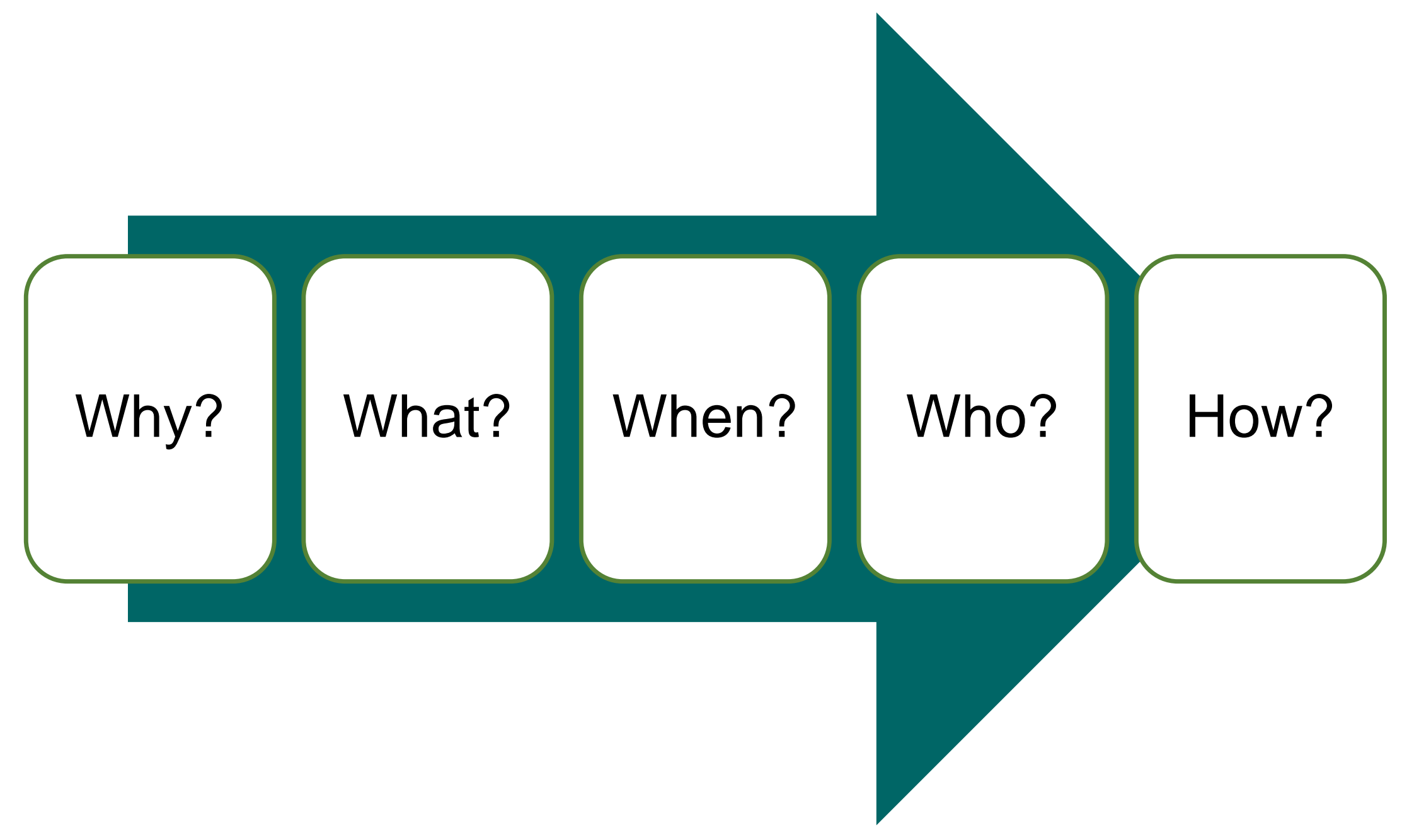




\section{Steps in \\ Data Collection}

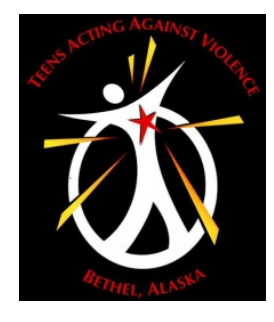

Why?

What?

When?

Who?

How? 


\section{Data Collection Frameworks}

- Population Indicators:

- Data on whole populations

- Example: 2013 Alaska Dashboard on Key Issues Impacting Domestic Violence and Sexual Assault (http://dps.Alaska.gov/CDVSA/dashboard.aspx)

- Performance Measures:

- Data on client populations

- Example: CDVSA Performance Details (http://omb.Alaska.gov/html/performance.html)

- Key Questions:

- Do you want data about everyone?

- Do you want data about clients only?

- Answer depends on why you want to collect data! 


\section{Example}

\section{Childhood Exposure to Domestic Violence}

\section{Percent of mothers whose $\mathbf{3}$ year old child saw violence or physical abuse}

Childhood Understanding Behaviors Survey (CUBS). Each year, over 1,000 mothers of three year old children are asked "Has your child ever experienced seeing violence or physical abuse in person?" Most current Alaska data is from 2011 and starting Alaska data is from 2009.

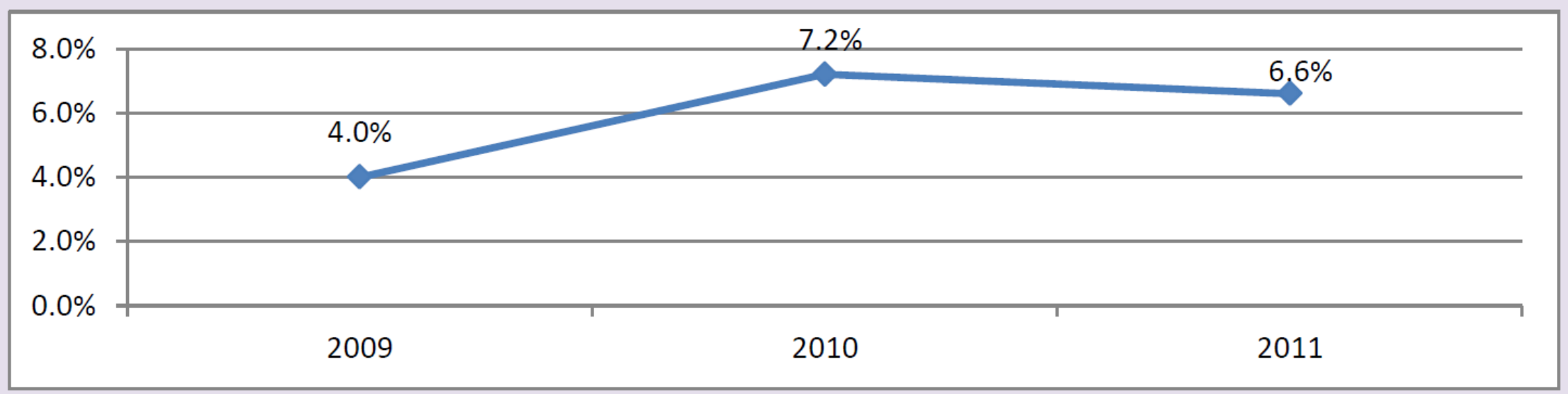

Progress needs improvement $\bigcirc$ because while there has been a small decline from the previous year, the violence exposure levels appear to be greater than they had been in 2009.

\section{- Population indicator or performance measure? - Why?}

Source: $h t t p: / / d p s$. Alaska.gov/CDVSA/dashboard.aspx 


\section{Example}

A1: Core Service - Safety - Victims are equipped to further access program services for safety, information, and protection when needed

Target \#1: As a result of contact with a victim service program, $80 \%$ of participants know more ways to plan for their safety

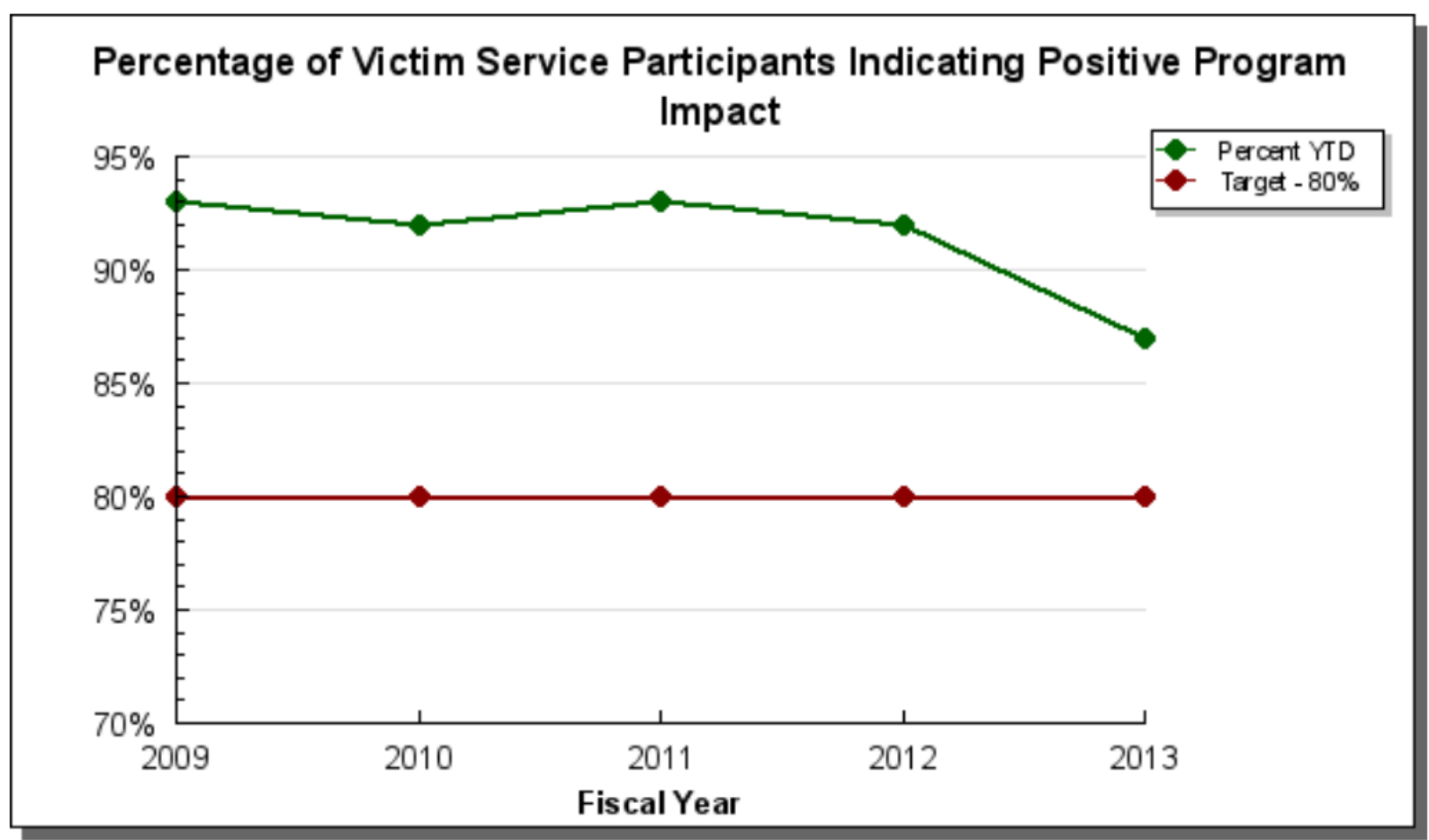

- Population indicator or performance measure?

- Why?

Source: http://omb.Alaska.gov/html/performance.html 


\section{Example}

Primary Prevention and Protective Factors

Primary prevention includes approaches before violence has occurred to prevent initial perpetration or victimization 14. Percent of schools implementing Fourth $\mathbf{R}$ healthy relationship curriculum

Department of Education \& Early Development (DEED). Percentage of public secondary schools that have teachers trained in the Fourth R| healthy relationship curriculum. Secondary schools include public high schools, middle schools, and alternative schools. Most current Alaska data is from state fiscal year 2013 and starting Alaska data is from state fiscal year 2011.

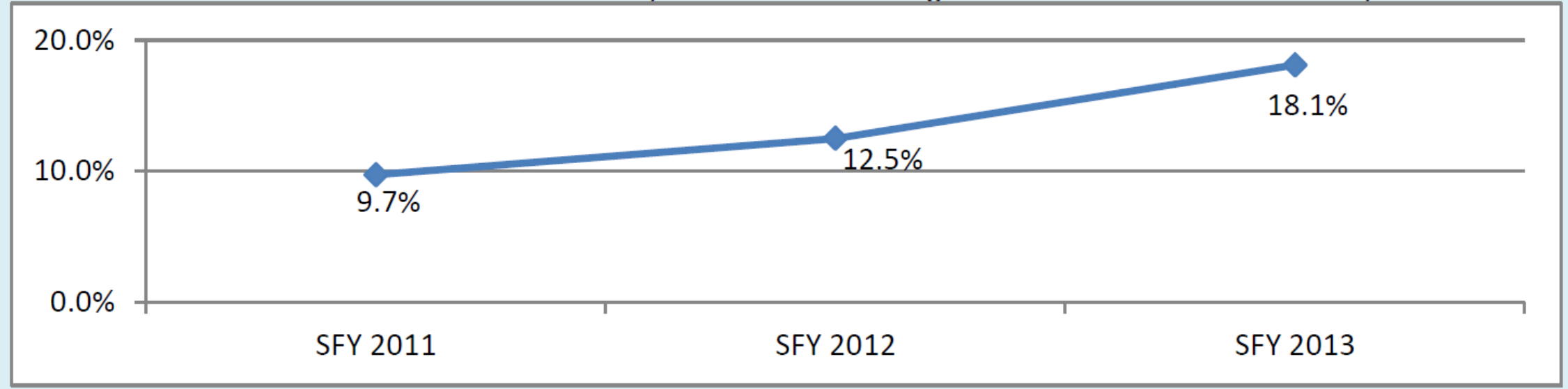

Progress is satisfactory $\bigcirc$ because this indicator is increasing steadily.

- Population indicator or performance measure?

- Why?

Source: http://dps.Alaska.gov/CDVSA/dashboard.aspx 


\section{Exercise:

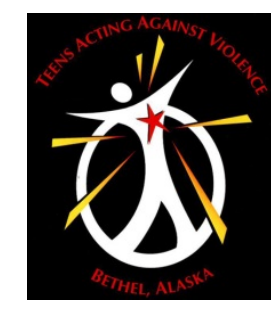

- Why collect data about impact of TAAV on population?

$\bullet$

$\bullet$

- Population Indicators:

$\bullet$

$\bullet$

$\bullet$

- Why collect data about impact of TAAV on participants?

- Performance Measures: 


\section{Another Framework: Logic Models}

\section{INPUTS}

\begin{tabular}{c|}
\hline $\begin{array}{c}\text { Program } \\
\text { investments }\end{array}$ \\
\hline
\end{tabular}

What we invest

\section{OUTPUTS}

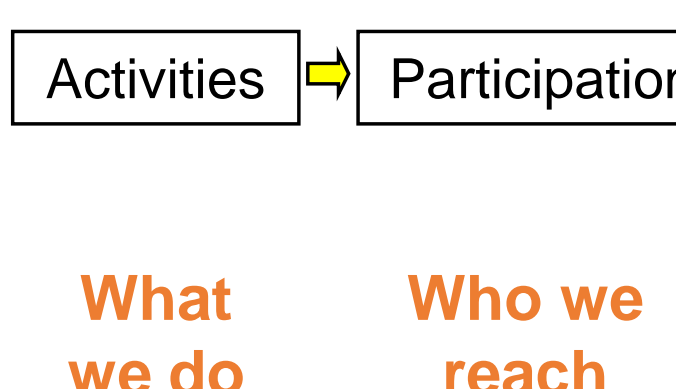

\section{OUTCOMES}

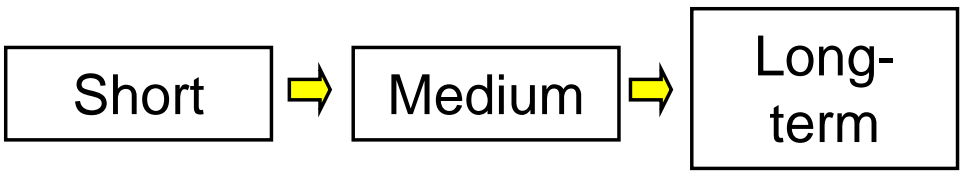

- In its simplest form, logic models examine:

- Inputs,

- Outputs, and

- Outcomes.

Source: http://www.uwex.edu/ces/pdande/progdev/

See also: http://dhss.alaska.gov/Commissioner/Grantees/Pages/logicmodel.aspx 


\section{Steps in \\ Data Collection}
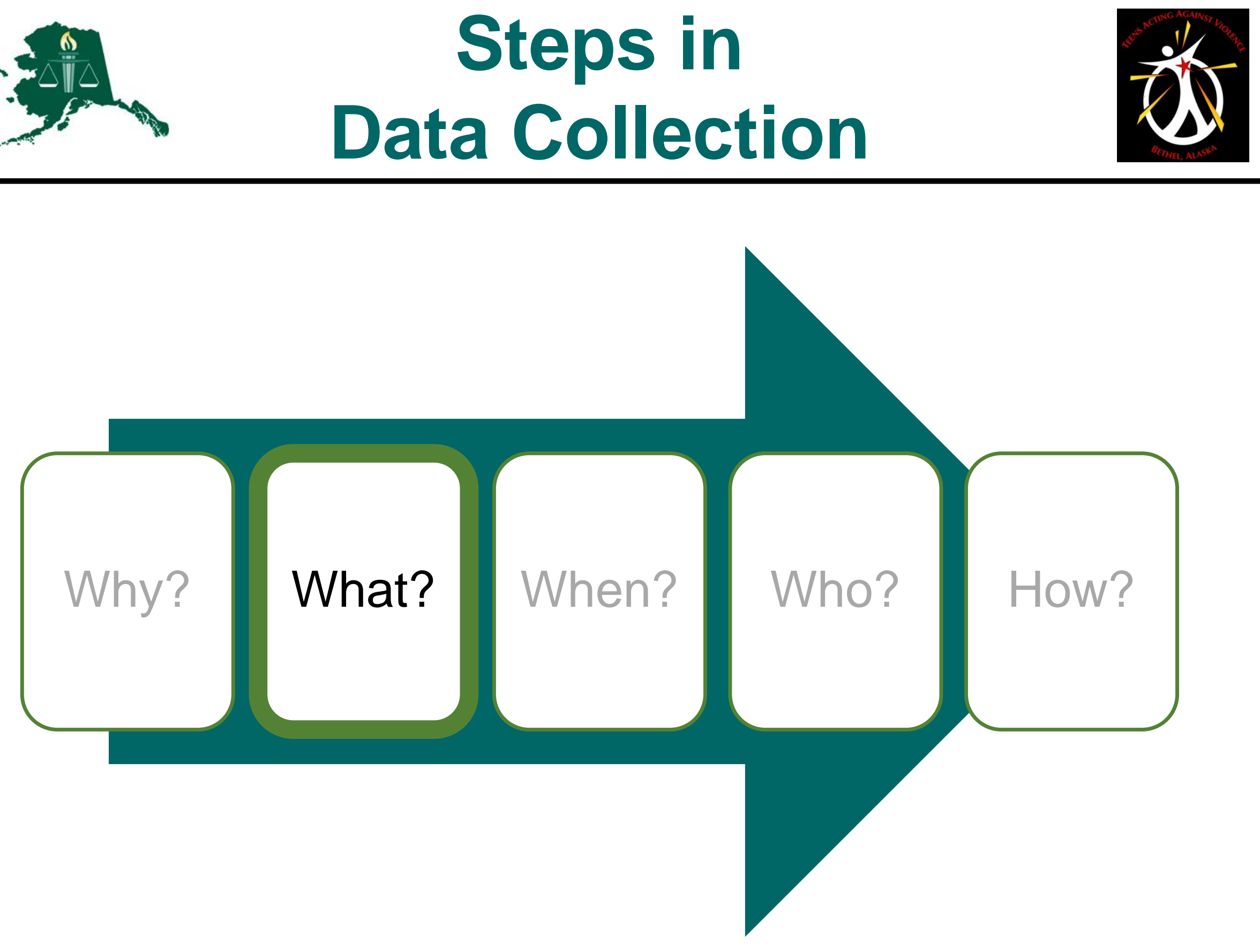


\section{Focus on

- Basic qualities of good performance measures:

- They are reliable (they provide consistent data)

- They are valid (they provide the right data)

- Did crisis counseling promote safety?

- Unreliable and invalid:

- I rarely don't feel good

- More reliable, but invalid:

- Since I came to the program, I feel better

- More reliable and more valid:

- Since I came to the program, I feel safer 


\section{ABC's of Question Construction}

- Use simple language

- Ask only about things that the respondents can be expected to know

- Make the question specific

- Define terms that are in any way unclear

- Avoid yes-no questions

- Avoid double negatives

- Don't ask double-barreled questions

- Use wording that has been adopted in validated surveys

- Include enough information to jog people's memories

- Emphasize information so people don't overlook parts of a question

- Use second-hand opinions only if first-hand information is not available

- Be sensitive to cultural differences

- Use questions that work well with different types of respondents Source: Weiss, C. H. (1998). Evaluation (2nd Ed.). Saddle River, NJ: Prentice Hall. 


\section{Exercise: What to Measure?}

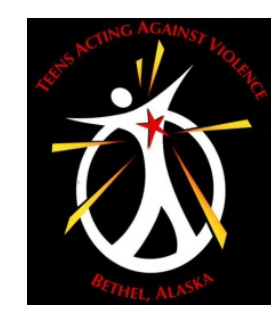

\section{Make these questions more reliable and more valid:}

- Does it seem possible or does it seem impossible to you that TAAV cannot prevent rape?

- Now that you've learned about healthy relationships, are you against unhealthy relationships?

- Don't you think that TAAV should receive financial assistance from OVC, OVW, or OJJDP through TLOA?

- TAAV is a culturally relevant program. Were you culturally sensitive?

- Since participating in TAAV, have you been a victim of sexual violence? 
- Three types of measures from TAAV participants:

- How much did the TAAV program do?

- How well did it do it?

- What impact did it have?

- Program participation

- Program satisfaction

- Impact of program activities 


\section{Program Participation}

- Frequency and length of participation

- Participation in TAAV program activities, such as:

- Outward Bound

- Meetings

- Village travel

- Helping with TWC events

- Making commercials / videos

- Lead On! conference

- Berry picking

- Camping

- Community presentations

- And many more! 


\section{Program Satisfaction}

- Overall opinion and satisfaction

- Cultural resonance

- TAAV staff members:

- Provided positive support

- Were knowledgeable

- Were respectful

- Favorite program activities

- Reasons for liking program activities

- Least favorite program activities

- Reasons for disliking program activities 


\section{Impact of Program Activities}

- Developing healthy relationships

- Resisting peer pressure

- Recognizing and avoiding abusive relationships

- Showing respect to others

- Openly expressing emotions and needs

- Using open communication skills

- Managing negativity

- Increasing honest communication 


\section{Steps in \\ Data Collection}
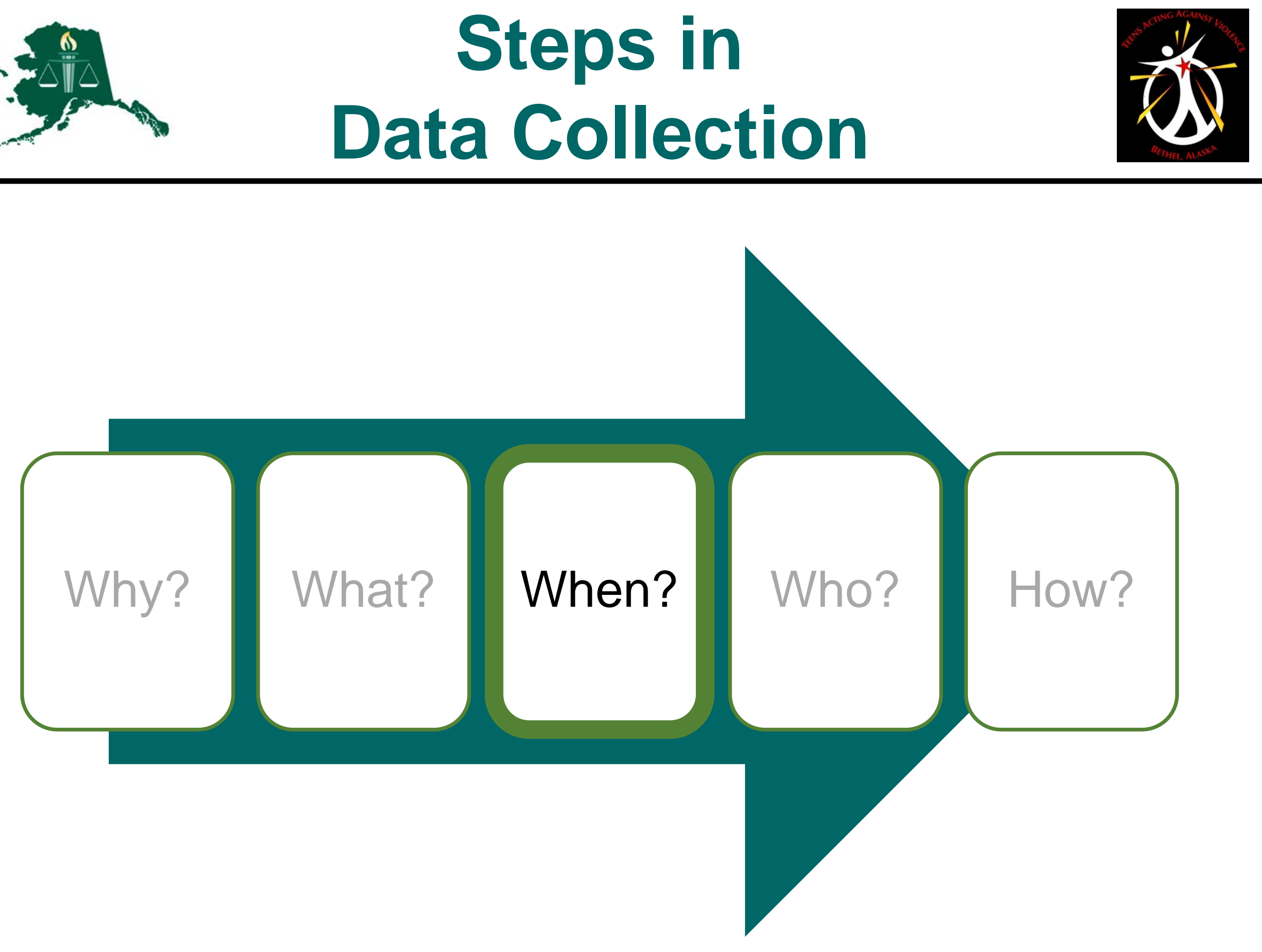


\section{When to Collect Data?}

- Obviously collect data after the program

- How long after the program?

- How many times after the program?

- Should you collect data before the program?

- Helpful to establish a baseline

- Helpful to document individual change over time

- But change cannot be attributed to program

- Should you collect data during the program?

- Helpful to document progress

- More helpful as a process measure than an outcome measure 


\section{Steps in \\ Data Collection}
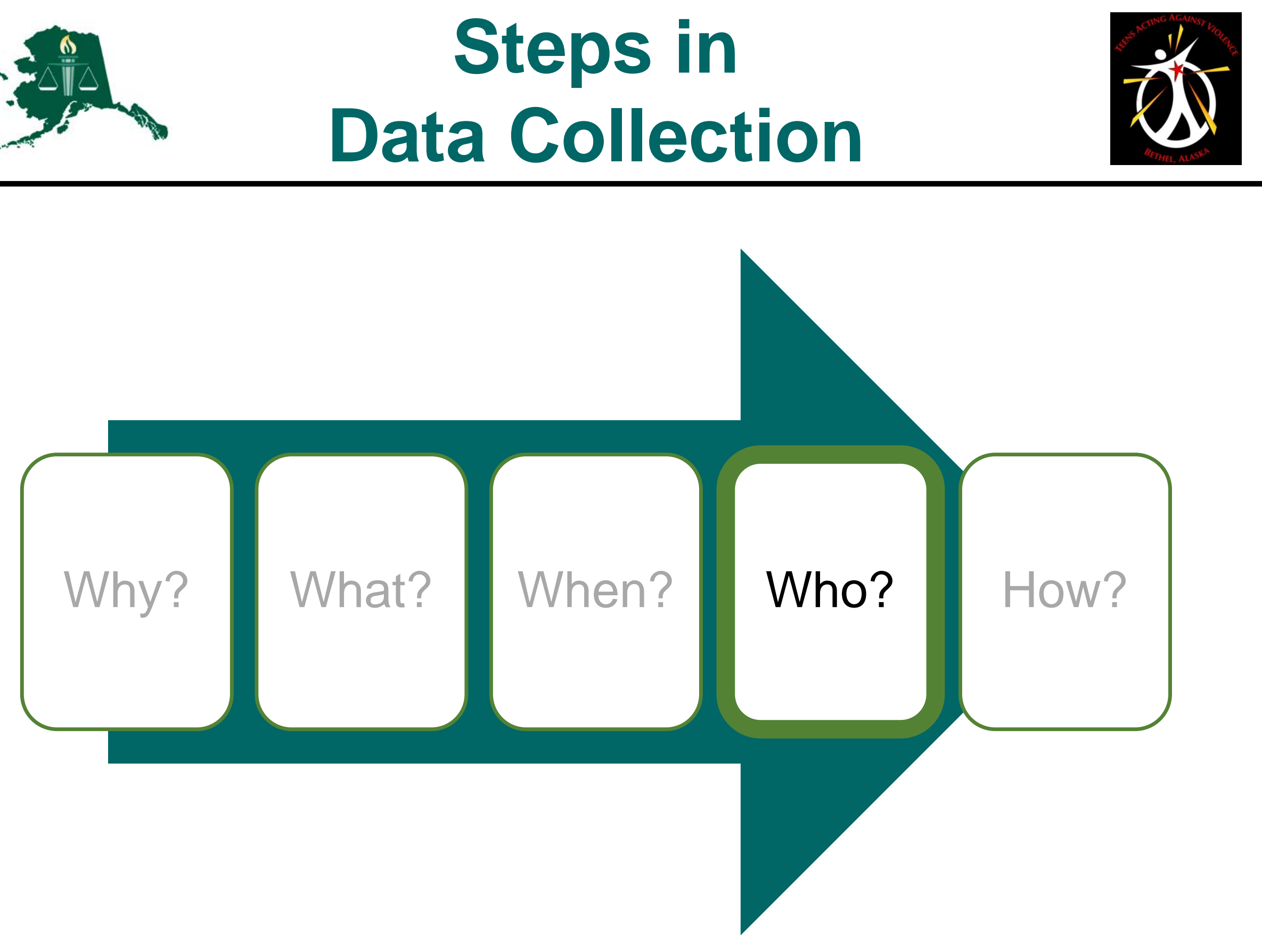


\section{Who to Collect Data From?}

- Obviously collect data from participants

- Should you collect data from non-participants?

- Useful to create a comparison group

- Improves internal validity - our ability to establish that the observed impact was caused by the program, not by other things

- Works only when people in the comparison group are similar to participants (or when very fancy statistical models are used)

- Ideally, people are randomly selected to be participants or non-participants 


\section{Special Considerations}

- Informed consent

- For youth: assent and parental consent

- Tribal authorization

- Selection and recruitment

- Use of incentives and compensation

- Voluntary participation

- Respondent safety and confidentiality

- Mandatory reporting

- Data storage and retention 


\section{TAAV Participants}

- Population: 86 TAAV members over the age of 18

- Sample: everyone included in population (85 participated)

- Criteria for participation:

- Must have participated in TAAV

- Must be 18 years old or older

- Must consent to participate in the survey

- Compensation:

- \$20 VISA gift card

- Five \$200 gift certificates to Alaska Airlines

- Recruitment: Social media (e.g., Facebook) 


\section{Steps in \\ Data Collection}
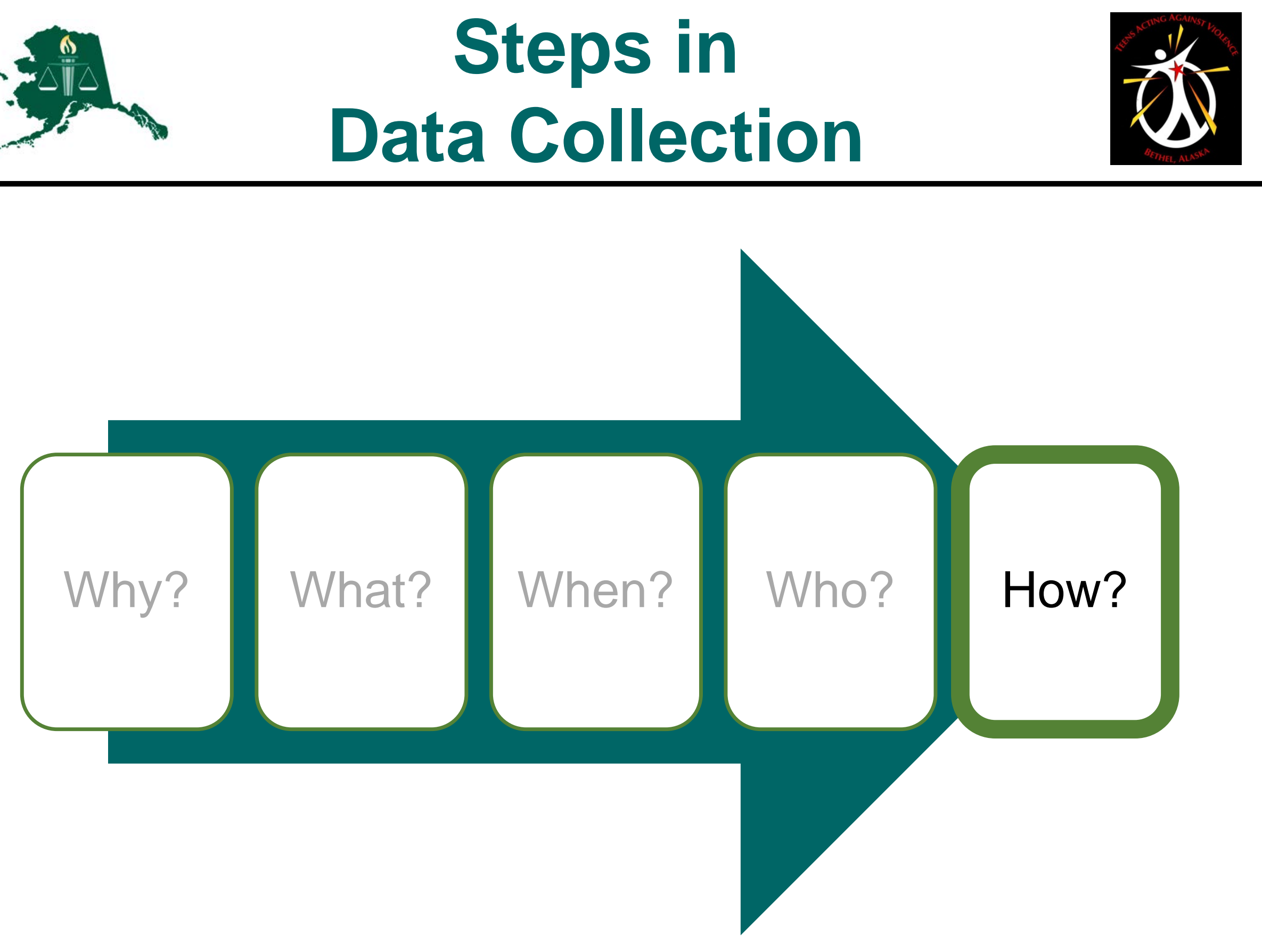


\section{Common Methods of Data Collection}

- Records, documents, and data files review

- Written questionnaires, surveys, and checklists

- Face-to-face interviews

- Telephone interviews

- Other collection methods:

- Observations

- Case studies

- Focus groups 


\section{The Secret to Successful Data Collection}

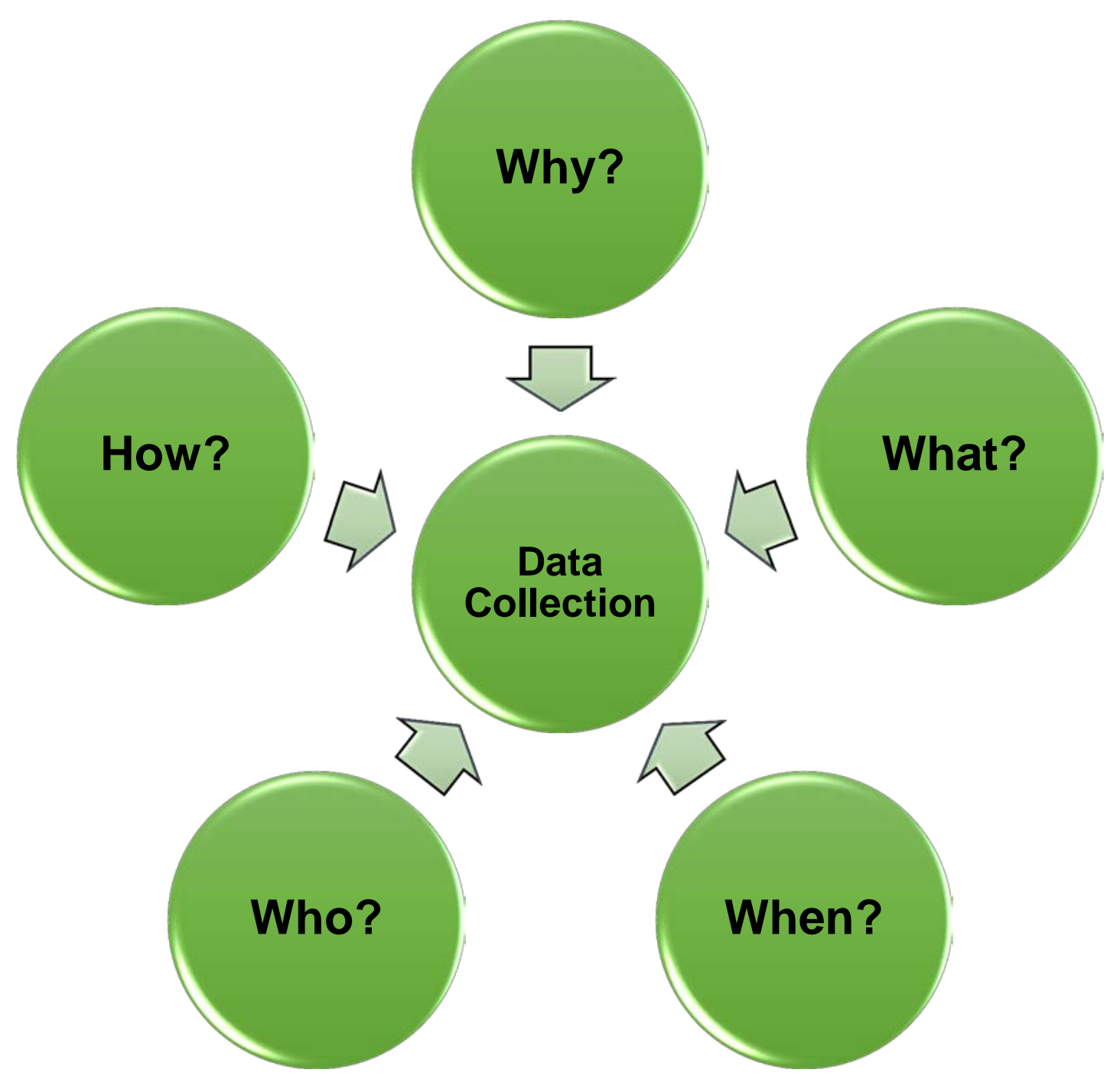




\section{Key Results: Impact of TAAV}

- Did TAAV increase ability to:

- Develop healthy relationships?

- Resist peer pressure?

- Recognize and avoid abusive relationships?

- Show respect to others?

- Did TAAV increase ability to intervene when witnessing:

- Controlling behaviors?

- Stalking behaviors?

- Bullying behaviors? 


\section{Key Results: Impact of TAAV}

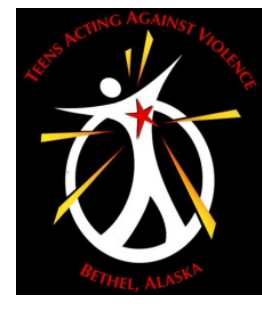

\section{Ability to develop healthy relationships}

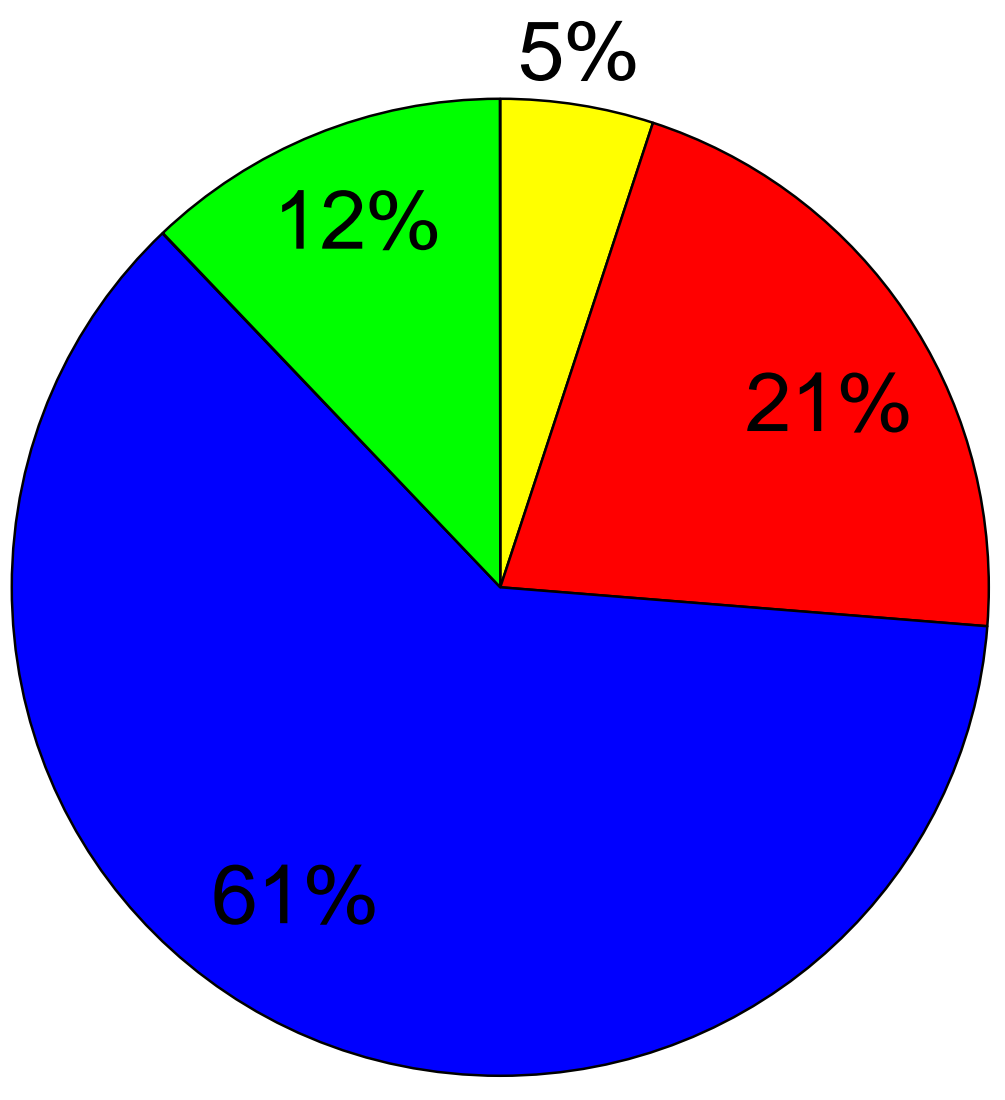

$\square$ No Gain

$\square$ Slight Gain

- Moderate Gain

$\square$ A lot of Gain 


\section{Key Results: Impact of TAAV}

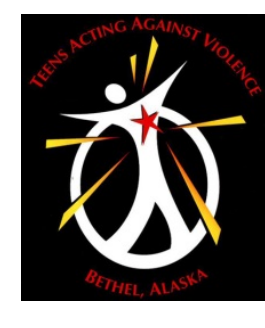

\section{Ability to resist peer pressure}

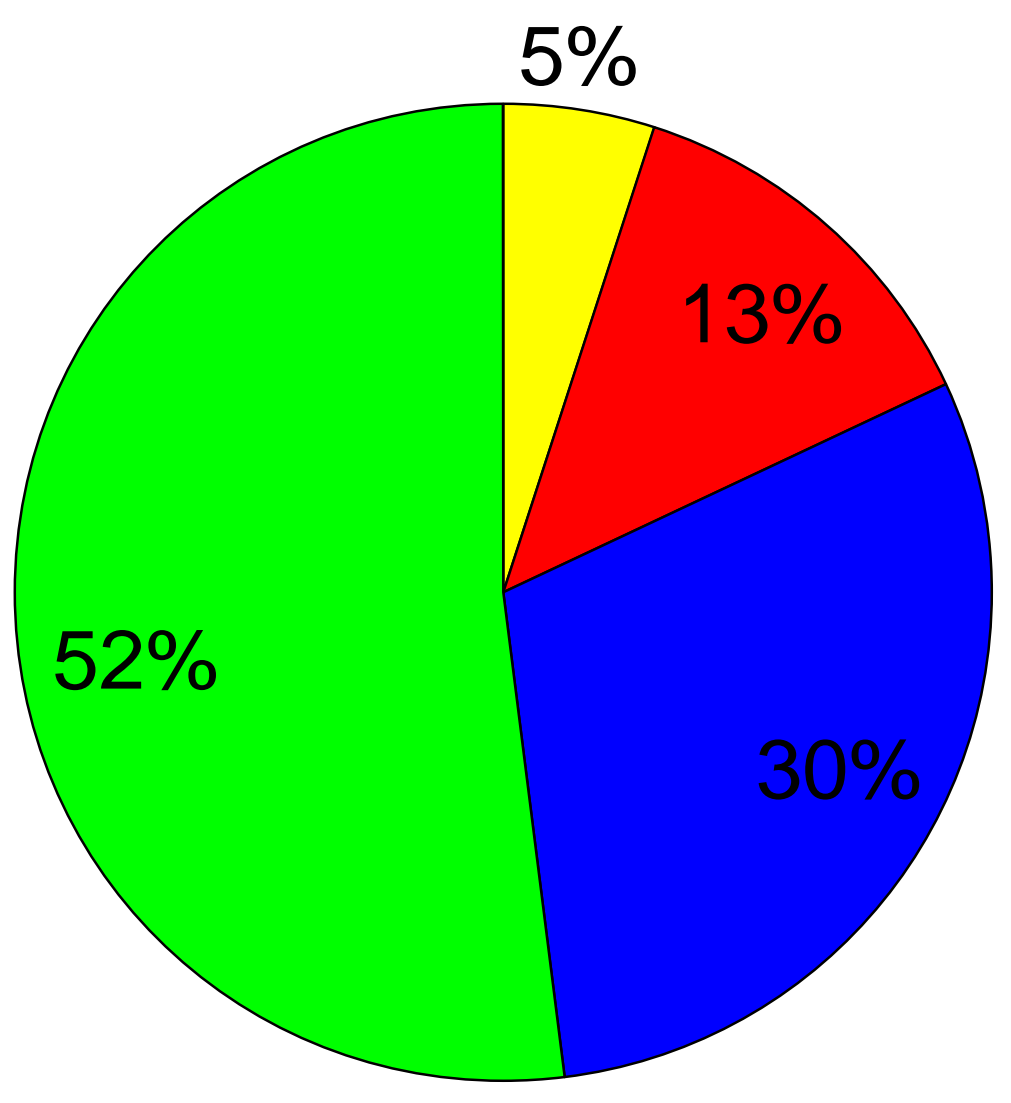

$\square$ No Gain

$\square$ Slight Gain

- Moderate Gain

$\square$ A lot of Gain 


\section{Key Results: Impact of TAAV}

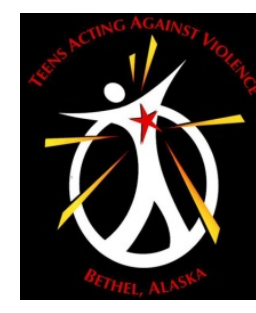

Ability to recognize and avoid abusive relationships

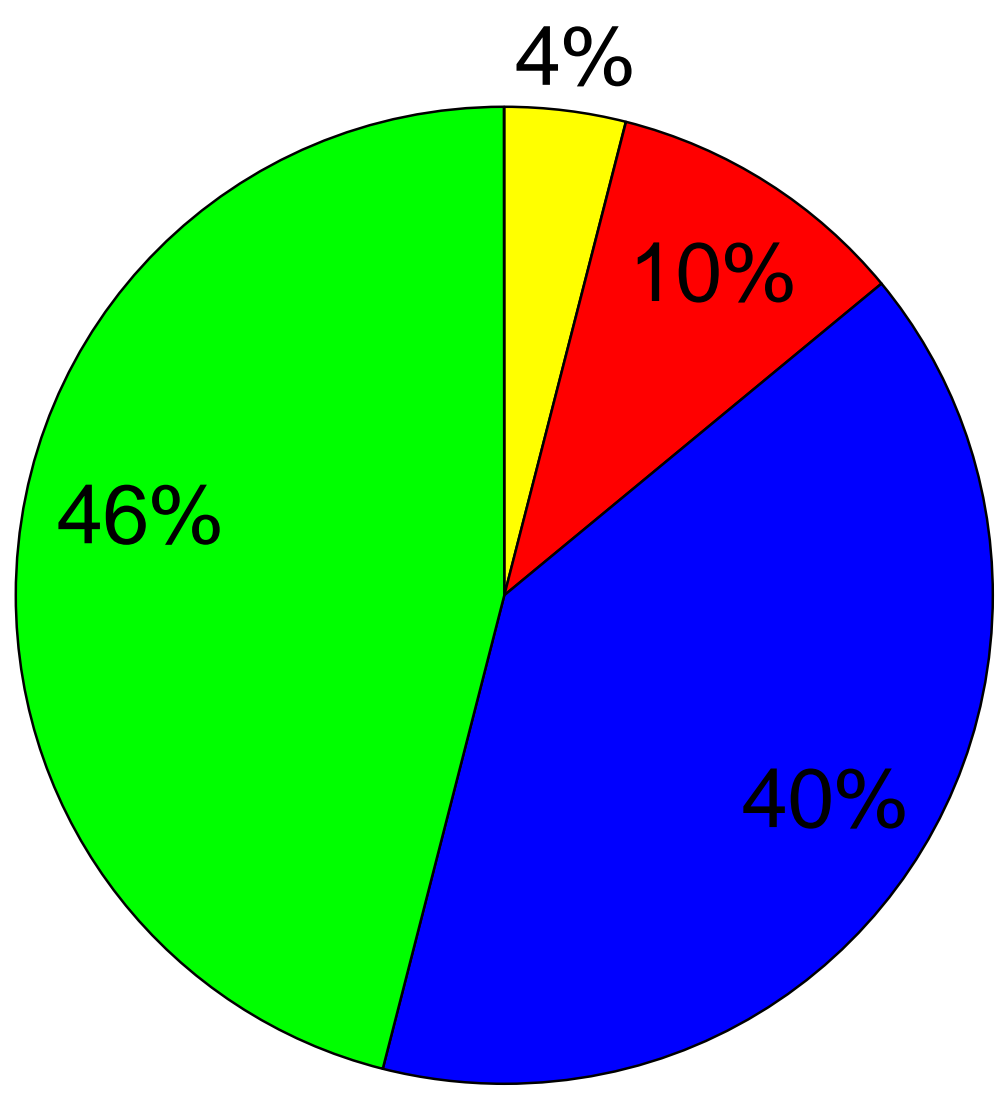

$\square$ No Gain

$\square$ Slight Gain

- Moderate Gain

$\square$ A lot of Gain 


\section{Key Results: Impact of TAAV}

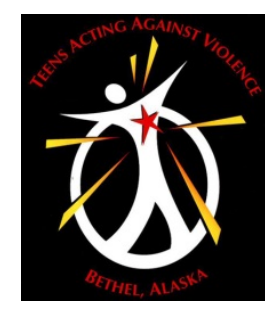

Ability to show respect to others

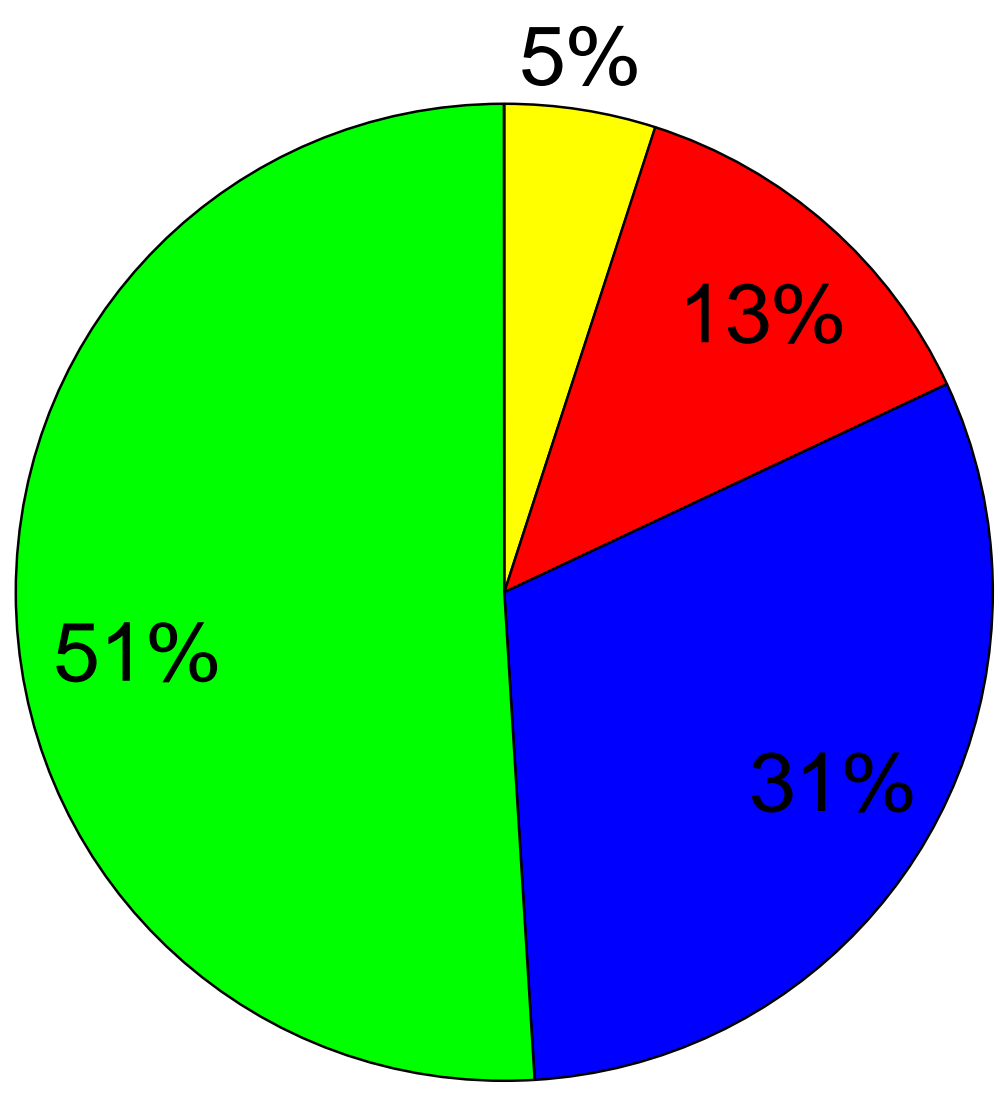

$\square$ No Gain

$\square$ Slight Gain

- Moderate Gain

$\square$ A lot of Gain 


\section{Key Results: Impact of TAAV}

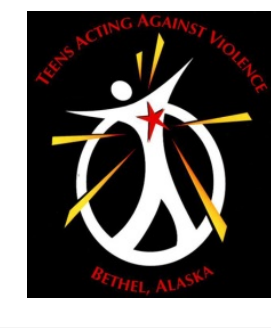

Ability to intervene when witnessing controlling behaviors

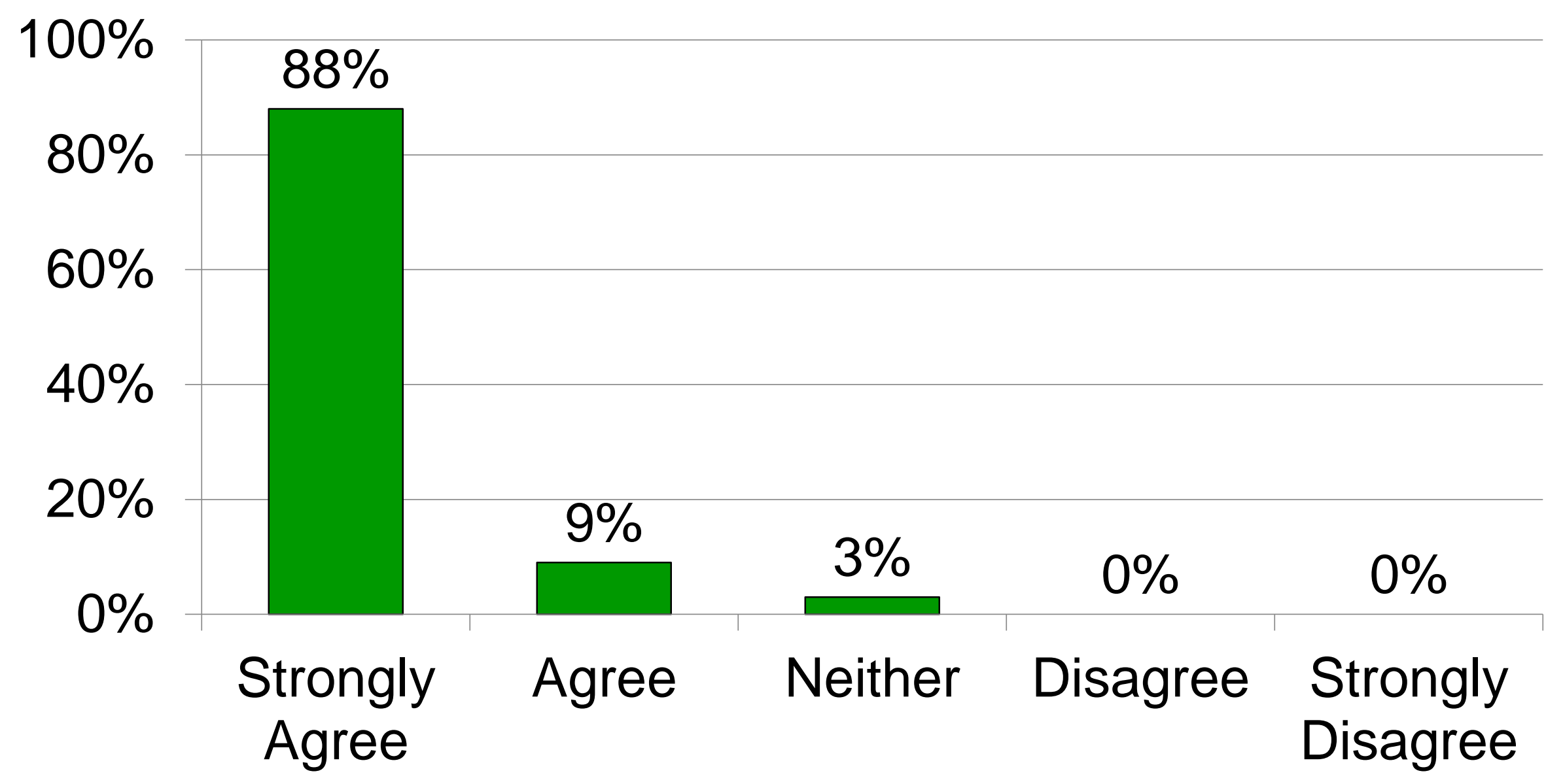




\section{Key Results: Impact of TAAV}

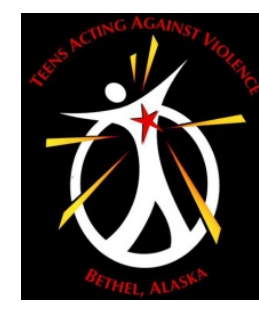

Ability to intervene when witnessing stalking behavior

$100 \%$

$80 \%$

$60 \%$

$40 \%$

$20 \%$

$0 \%$

\section{$86 \%$}

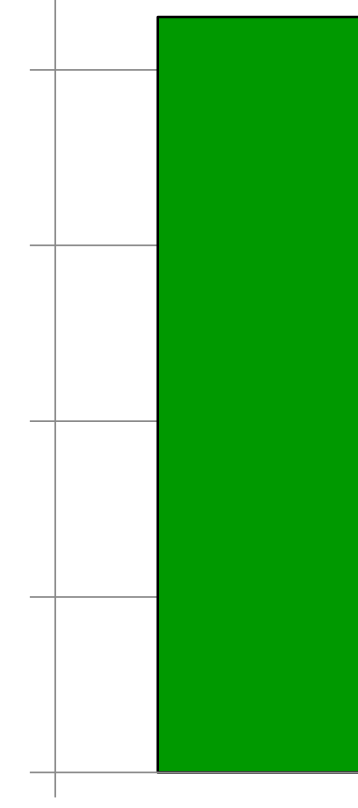

$14 \%$

$0 \%$

$0 \%$

$0 \%$

Strongly Agree

Agree Neither Disagree 


\section{Key Results: Impact of TAAV}

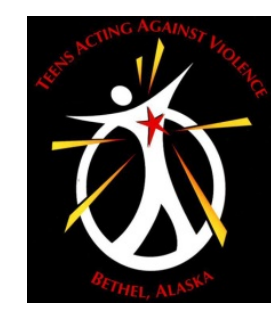

Ability to intervene when witnessing bullying behavior

$100 \%$

$80 \%$

$60 \%$

$40 \%$

$20 \%$

$0 \%$

$69 \%$

$20 \%$

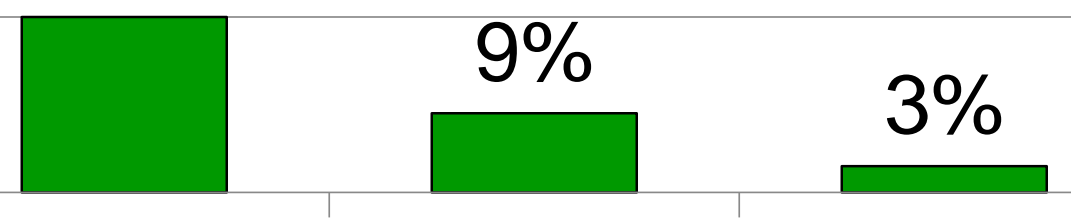

$0 \%$

Strongly Agree

Agree Neither Disagree

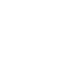




\section{Key Results: Impact of TAAV}

- Overall, TAAV increased ability to:

- Develop healthy relationships,

- Resist peer pressure,

- Recognize and avoid abusive relationships,

- Show respect to others,

- Intervene when witnessing controlling behaviors,

- Intervene when witnessing stalking behaviors, and

- Intervene when witnessing bullying behaviors.

- Lots of other positive results!

- Also have important limitations:

- Only collected data after the program (no baseline)

- Only collected data from participants (no comparison group) 


\section{Contact Information}

Andre B. Rosay

Justice Center, University of Alaska Anchorage

abrosay@uaa.alaska.edu

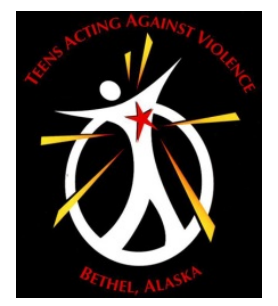

Michelle DeWitt

Bethel Community Services Foundation

michelle@bcsfoundation.org 